5 Myles PS, Hunt JO, Nightingale CE, et al. Development and psychometric testing of a quality of recovery score after general anesthesia and surgery in adults. Anesth Analg 1999; 88: 83-90.

\section{Anesthesia in the prone lithotomy position}

\section{To the Editor:}

We present our experience of the anesthetic management of patients in the rarely used prone lithotomy position (Figure).

During surgery, the prone position, if correctly applied, ensures free abdominal movement, is not associated with adverse effects on respiratory mechanics and improves lung volume and oxygenation. ${ }^{1,2}$ The lithotomy position, when superimposed on the prone position, improves cardiac output and hemodynamics, compensating for the decreased cardiac output due to impaired venous return in the prone position. ${ }^{3}$ Repair of a vesico-vaginal fistula under balanced anesthesia was performed in the prone lithotomy position in three ASA physical status I and II patients. In all cases, non-invasive blood pressure, central venous presure (CVP), ECG, airway pressure, end tidal carbon dioxide and oxygen saturation were monitored and changes in hemodynamic and respiratory variables were recorded. After the change of position to prone lithotomy, all variables remained stable except for a rise in airway pressure in the range of +1 to $+2 \mathrm{~cm} \mathrm{H}_{2} \mathrm{O}$ in one patient but without change in end tidal carbon dioxide tension and oxygen saturation. Another patient had a moderate rise of $\mathrm{CVP}\left(+2\right.$ to $\left.+5 \mathrm{~cm} \mathrm{H}_{2} \mathrm{O}\right)$. Peripheral nerve injury did not occur in any of the patients. The variables returned to baseline levels after patients were placed in the supine position after surgery, before extubation.

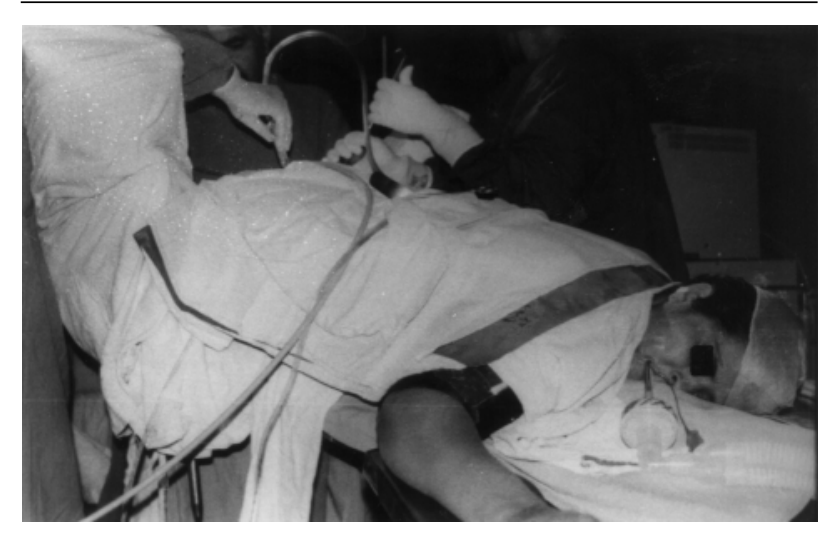

FIGURE Surgical repair of vesico-vaginal fistula in the prone lithotomy position.
On the basis of the experience gained during these three cases, we suggest that surgery in the prone lithotomy position is not associated with major cardiovascular or respiratory derangements intraoperatively.

Shashi Srivastava MD

Chandra Kant Pandey MD

Lucknow, India

\section{References}

1 Pelosi P, Croci M, Calappi E, et al. The prone positioning during general anesthesia minimally affects respiratory mechanics while improving functional residual capacity and increasing oxygen tension. Anesth Analg 1995; 80: 955-60.

2 Pelosi P, Croci M, Calappi E, et al. Prone positioning improves pulmonary function in obese patients during general anesthesia. Anesth Analg 1996; 83: 578-83.

3 Cucchiara RF, Ronal JF. Patient positioning. In: Miller RD (Ed). Anesthesia, 5 ed. New York: Churchill Livingstone Inc., 1999: 1017-32.

4 Thompson JD. Vesicovaginal and urethrovaginal fistula. In: Rock JA, Thompson JD (Ed). Te Linde's Operative Gynecology, $8^{\text {th }}$ ed. Philadelphia: Lippincott-Raven,

1997: 1175-1205.

\section{Cost and resource implications of under- graduate simulator-based education}

To the Editor:

Medical education has been recognized as a costly undertaking especially when innovations are introduced. Rothman and Cohen point out that standardized assessments like the Objective Structured Clinical Examinations (OSCE) are logistically complex and expensive. ${ }^{1}$ Interest in the use of anesthesia simulators for both educational and assessment purposes has increased as more medical schools acquire this technology. However, issues related to the financial and faculty resources cannot be ignored.

TABLE Estimation of operational costs

\begin{tabular}{lll}
\hline Item & Annual cost & $\begin{array}{l}\text { Cost per } \\
\text { student } \\
(C d n \$)\end{array}$ \\
\hline Simulator equipment and supplies & $3,500.00$ & 19.77 \\
Computer operator & $4,500.00$ & 25.42 \\
$\mathrm{CO}_{2}$ cylinders & 300.00 & 1.69 \\
Videotapes & 180.00 & 1.02 \\
Office equipment and supplies & 324.00 & 1.83 \\
Total & $8,804.00$ & 49.73 \\
\hline
\end{tabular}


Financial and faculty resource data of undergraduate simulator-based education and evaluation projects for the period from July 1997-April 2001 at the University of Toronto were reviewed. Operational costs for upkeep and maintenance of the anesthesia simulator as well as faculty resources required were assessed. An average cost per student was calculated based on a cohort of ten students per daily session for a total of 177 students.

Annual operational costs are found in the Table. For educational purposes alone, faculty resources totalled $344 \mathrm{hr}$ per annum and 1.94 faculty hr per student. For evaluation purposes, two faculties per session were required thereby doubling the faculty hours from 216 to $432 \mathrm{hr}$ per annum.

The financial and resource cost per student appears high. However, comments from medical students at the University of Toronto strongly endorsed the implementation of simulation technology into the curriculum. ${ }^{2}$ Faculty, as well, highly rated the simulation program as an excellent learning experience and a potential tool for undergraduate standardized assessments. We believe that the quality of the simulator educational experience justifies its use.

Pamela J. Morgan MD CCFP FRCPC

Doreen M. Cleave-Hogg

Toronto, Ontario

\section{References}

1 Rothman A, Cohen R. Understanding the objective structured clinical examination: issues and options. Annals RCPSC 1995; 28: 28-7.

2 Morgan PJ, Cleave-Hogg D. A Canadian simulation experience: faculty and student opinions of a performance evaluation study. Br J Anaesth 2000; 85: 779-81.

\section{Anesthesia for a child with Antler- Bixler syndrome}

To the Editor:

Antley-Bixler syndrome is characterized by the association of craniofacial dysmorphism, including brachycephaly and midface hypoplasia, with a bilateral radiohumeral synostosis. ${ }^{1,2}$ We anesthetized a child with this syndrome three times within three years and discuss the problems of anesthetic management.

The syndrome was diagnosed at birth. Cranioplasty and fronto-orbital advancement were required three times. The first, second and third operations were per- formed at five, 18 and 32 months, respectively. During the first operation, anesthesia was induced with sevoflurane and nitrous oxide in oxygen by mask, but mask ventilation became difficult due to upper airway obstruction. A laryngeal mask airway (LMA) (size \#1) was inserted immediately without difficulty and ventilation via the LMA was easy. In the second and third operations, anesthesia was also induced with sevoflurane and nitrous oxide in oxygen by mask, but the child's trachea was intubated immediately without muscle relaxants. Since the vocal cords could not be seen by direct laryngoscopy, blind endotracheal intubation was performed.

In giving anesthesia to a child with this syndrome, it is difficult to maintain a patent airway. ${ }^{3}$ We chose a slow induction of anesthesia but, nonetheless, mask ventilation became difficult. The vocal cords could not be seen by direct laryngoscopy and intubation was also difficult. However, the LMA proved to be useful to secure the airway. Preoperative evaluation of the airway is important with this syndrome, especially in children, and the LMA may be helpful for the management of these patients.

Munehiro Shiraishi MD

Kouichiro Minami D PhD

Kitakyushu, Fukuoka, Japan

\section{References}

1 Antley R, Bixler D. Trapezoidocephaly, midfacial hypoplasia and cartilage abnormalities with multiple synostoses and skeletal fractures. Birth Defects 1975; 11: 397-401.

2 Hassell S, Butler MG. Antley-Bixler syndrome: report of a patient and review of the literature. Clin Genet 1994; 46: 372-6.

3 Vaughan C. Anesthetic management of children with craniofacial anomalies. CRNA 1997; 8: 123-34.

\section{Second gas effect of $\mathrm{N}_{2} \mathrm{O}$}

\section{To the Editor:}

Nishikawa et al. ${ }^{1}$ recently addressed the issue of the second gas effect of $\mathrm{N}_{2} \mathrm{O}$ on oxygen uptake. The authors reported an increase in $\mathrm{FETO}_{2}$ and arterial oxygen tension $\left(\mathrm{PaO}_{2}\right)$ five minutes after $\mathrm{N}_{2} \mathrm{O}$ inhalation, which they interpreted as such a second gas effect.

There are, however, some serious methodological issues in their experiments that not only cloud the authors' interpretation of their findings, but also provide no definitive evidence of a second gas effect of $\mathrm{N}_{2} \mathrm{O}$ on oxygen uptake. 